\title{
Effect of high intensity interval training on 8-oxoguanine DNA glycosylase and 8-hydroxy-2'-deoxyguanosine contents in the brain and liver of rats
}

\author{
Ehsan Afroozi-Gerow ${ }^{1}$, Mohammad Esmaiel Afzalpour ${ }^{1}$, Hossein TaheriChadorneshin ${ }^{2 *}$, Seyed Hosein Abtahi-Eivary ${ }^{3}$ \\ ${ }^{1}$ Department of Sport Sciences, University of Birjand, Birjand, Iran. \\ ${ }^{2}$ Department of Sport Sciences, University of Bojnord, Bojnord, Iran. \\ ${ }^{3}$ Department of Clinical Biochemistry, Gonabad University of Medical Sciences, Gonabad, Iran.
}

\begin{tabular}{|c|c|}
\hline ARTICLE INFO & ABSTRACT \\
\hline Article history: & \multirow{11}{*}{ 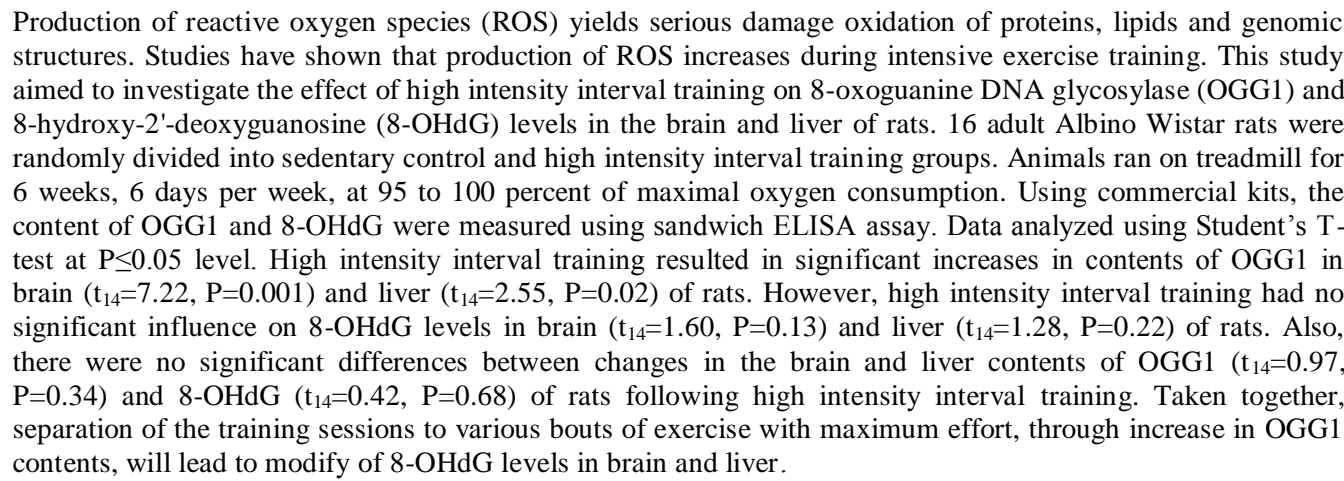 } \\
\hline Received on: $02 / 08 / 2016$ & \\
\hline Revised on: 13/09/2016 & \\
\hline Accepted on & \\
\hline Available online: $29 / 10 / 2016$ & \\
\hline Key words: & \\
\hline High intensity interval & \\
\hline training, 8-oxoguanine DNA & \\
\hline glycosylase, 8-hydroxy-2'- & \\
\hline & \\
\hline Brain. & \\
\hline
\end{tabular}

\section{INTRODUCTION}

The positive effects of exercise training on various organelles of body have been documented. However, it appears that exercise, especially intensive exercise training, has potential to increase production of reactive oxygen species (ROS) through increases in oxygen consumption (Ogonovszky et al., 2005a, 2005b). This occurrence subsequently yields serious damage oxidation of proteins, lipids and genomic structures (Radak et al., 2006, 2008, Nikolaidis et al., 2009). ROS increases oxidative base lesions within DNA structure, and eventually cell arrest, apoptosis, and necrosis (Radak et al., 2003). Guanine is prone to undergo further oxidation upon exposure to hydroxyl radicals

\footnotetext{
* Corresponding Author

Hossein TaheriChadorneshin, 4 Km of Bojnord-Esfarāyen Highway, Bojnord, Iran.Tel:+985832284610,E-mail:h.taheri@ ub.ac.ir
}

due to its lower redox potential compare to other nucleic acid bases. Therefore, 8 -hydroxy-2'-deoxyguanosine $(8-\mathrm{OHdG})$ is one of the most frequently generated oxidative base lesions (Radak $e t$ al., 2011). Unrepaired 8-OHdG can lead to transversion of G : C to $\mathrm{T}: \mathrm{A}$ and cause mutation. $8-\mathrm{OHdG}$ level increases during many diseases such as cancer, atherosclerosis, diabetes and Alzheimer's disease (Ogonovszky et al., 2005a; Radak et al., 2007, 2008). To cope with such detrimental consequences, cells are equipped with DNA repair system to reduce the effects of these oxidative DNA damages. Major mammalian DNA glycosylase for recognizes and cleaves of oxidized guanine from DNA is 8-oxoguanine DNA glycosylase (OGG1) (Radak et al., 2007, 2011). Many factors influence on OGG1 and 8-OHdG levels including maximum oxygen consumption $\left(\mathrm{VO}_{2} \mathrm{max}\right)$ (Loft et al., 1994), body mass index (BMI) (Kasai et al., 2001) and exercise training (Ogonovszky et al., 2005a; Koltai et al., 2011). 
In context of exercise training, it has been shown that 2 months of regular treadmill running reduces 8 -OHdG in the nuclear and mitochondrial DNA and increases OGG1 activity in the liver of old rats (Nakamoto et al., 2007). Another study has demonstrated a significantly higher OGG1 activity in the red type of skeletal muscle compare with white fibers in old rats following 8 weeks running on treadmill (Radak et al., 2007). Interestingly, 8 weeks swimming has been increased OGG1 levels/activity in the nucleus and mitochondria, whereas 8 weeks detraining reverses the up-regulating effect of training (Radak et al., 2009). Besides, elevation of OGG1 and 8-OHdG levels in liver of rats has been reported following overtraining (Ogonovszky et al., 2005a). In contrast, neither insulin-like growth factor-1 (IGF-1) supplementation and nor exercise training with $60 \%$ of $\mathrm{VO}_{2} \max$ had not any effect on OGG1 and $8-\mathrm{OHdG}$ levels. However, combination of exercise and IGF-1 Supplementation increased acetylated OGG1 levels in hippocampus of old rats (Koltai et al., 2011).

Evidences suggest that high-intensity exercise training (HIIT) increases superoxide dismutase (SOD), glutathione peroxidase (GPx) activity in soleus muscle (Criswell et al., 1993) and reduces malondialdehyde (MDA) levels in fast-twitch extensor digitorum longus muscle (Cunningham et al., 2005). Because of insufficient information regarding the health effects of HIIT on OGG1 and 8-OHdG, the results of present study will give new insights about HIIT. Especially, greater stress oxidative occurs during HIIT due to activation of NADPH oxidase (Haram et al., 2009), xanthine oxidase (Kostaropoulos et al., 2006), and hypoxic conditions (Rasmussen et al., 2009). In addition, liver and brain are considered as redox sensitive organs in body due to large number of mitochondria, ischemia/reperfusion of blood (Cooper et al., 2002, Lamprecht et al., 2004) and large amounts of iron and copper ions (Cooper et al., 2002, Urso et al., 2003). Collectively, the purpose of this study was to investigate the effect of HIIT on OGG1 and 8-OHdG levels in the liver and brain of rats.

\section{MATERIALS AND METHODS}

\section{Animals and HIIT protocol}

Sixteen pathogen-free adult (3 months old) male albino Wistar rats (purchased from the laboratory of bearing and multiplying at the Mashhad University of Medical Sciences, Iran) were randomly divided into either control (C) or high intensity interval training (HIIT) groups. All animal experiments conformed to the guidelines for the use and care of laboratory animals ("Principles of laboratory animal care",NIH publication No. 86-23. Revised 1996). Rats had free access to water and food and kept in room with $25 \pm 2{ }^{\circ} \mathrm{C}$ and a $12 \mathrm{~h}$ light/12 h dark cycle. After familiarization with walking on motor-driven treadmill (5 days, 10 $\mathrm{min} /$ day at $10 \mathrm{~m} / \mathrm{min}$ ), rats were performed intensive interval training based on overload principle for 6 weeks, 6 session per weeks at 95-100\% $\mathrm{VO}_{2} \max$ (Afzalpour et al., 2015). In even days, rats were submitted to running at $40 \mathrm{~m} / \mathrm{min}$ ( $3 \mathrm{~min}, 2$ interval in first session and progressively increased to 6 repetitions in the 6 th week). In odd days, rats were submitted to running at $54 \mathrm{~m} / \mathrm{min}$ (30 s, 3 intervals in first session and progressively increased to 20 repetitions in the 6th week), respectively (Afzalpour et al., 2015). Warm-up and cool-down were performed at $16 \mathrm{~m} / \mathrm{min}$ for 3 minutes.

Also, Active rest was performed between intervals in HIIT group for $60 \mathrm{~s}$ at $16 \mathrm{~m} / \mathrm{min}$. Intensities of active rest and interval training correspond to 68 and 95-100\% $\mathrm{VO}_{2} \mathrm{max}$, respectively (Afzalpour et al., 2015). Mild electric shock (0.5 mA, $1 \mathrm{HZ}$ ) and soft sponge were used to stimulate the animals to run (Radak et al., 2007). The rats of the $\mathrm{C}$ group were exposed to the same environment as HIIT groups without running (Ogonovszky et al., 2005b).

\section{Tissue preparation and Biochemical assays}

Rats were sacrificed under deep anesthesia (Ketamine, 60-80 mg/kg and Xylazine, $8 \mathrm{mg} / \mathrm{kg}$; IP) $48 \mathrm{~h}$ after last exercise session. The whole brain and liver rat was removed, washed by normal saline, and finally stored at $-80^{\circ} \mathrm{C}$. Brain and liver were smashed into a fine powder by liquid nitrogen (Afzalpour et al., 2015). Then, $1 \mathrm{ml} 1 \times$ phosphate buffered saline and protease inhibitor cocktail (\#GB-326-1, ProBlock ${ }^{\mathrm{TM}}-50$, Goldbio technology CO, USA) added to the microtubes. Commercially 96well ELISA kits were used to measure the content of OGG1 (\#CSB-EL016313RA, Cusabio Biotech CO., LTD. SinoAmerican) and 8-OHdG levels (\#CSB-E10526r, Cusabio Biotech CO., LTD. Sino-American). The sensitivities of OGG1 and 8OHdG were less than $6.25 \mathrm{pg} / \mathrm{ml}$ and $0.078 \mathrm{ng} / \mathrm{ml}$, respectively. The assays were carried out according to the manufacturer's instructions. Contents were expressed in $\mathrm{mg}$ tissue weight.

\section{Statistical analysis}

Data were analyzed in SPSS software (version 16.0), expressed as means \pm standard deviation. Initially, normality of distribution of dependent variables was approved by ShapiroWilk's test. Then, statistical significance was calculated using Student's t-test. Significance level was set at $\mathrm{p}<0.05$.

\section{RESULTS}

The results indicated a significant increases in OGG1 contents of brain $(22.62 \pm 3.29$ vs. $11.40 \pm 2.89 \mathrm{pg} / \mathrm{mg}$ for HIIT and $\mathrm{C}$ groups respectively; $\mathrm{t}_{14}=7.22, \mathrm{P}=0.001$ ) (Fig. 1A) and liver $(48 \pm 7.66$ vs. $40.33 \pm 3.69 \mathrm{pg} / \mathrm{mg}$ for HIIT and $\mathrm{C}$ groups respectively; $\mathrm{t}_{14}=2.55, \mathrm{P}=0.02$ ) (Fig. $1 \mathrm{~B}$ ).

In contrast, intensive interval training had no significant effect on $8-\mathrm{OHdG}$ levels of brain $(0.23 \pm 0.07$ vs. $0.29 \pm 0.08 \mathrm{ng} / \mathrm{mg}$ for HIIT and $\mathrm{C}$ groups respectively; $\mathrm{t}_{14}=1.60, \mathrm{P}=0.13$ ) (Fig. 2A) and liver $(0.77 \pm 0.15$ vs. $0.88 \pm 0.11 \mathrm{ng} / \mathrm{mg}$ for HIIT and $\mathrm{C}$ groups respectively; $\mathrm{t}_{14}=1.28, \mathrm{P}=0.22$ ) (Fig. $2 \mathrm{~B}$ ).

Also, in comparison of two tissues, our results did not show any significant differences in change of protein content of OGG1 $\left(\mathrm{t}_{14}=0.97, \mathrm{P}=0.34\right)$ and $8-\mathrm{OHdG}\left(\mathrm{t}_{14}=0.42, \mathrm{P}=0.68\right)$ between brain and liver following HIIT. 

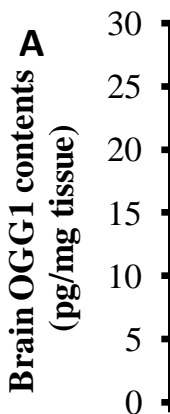

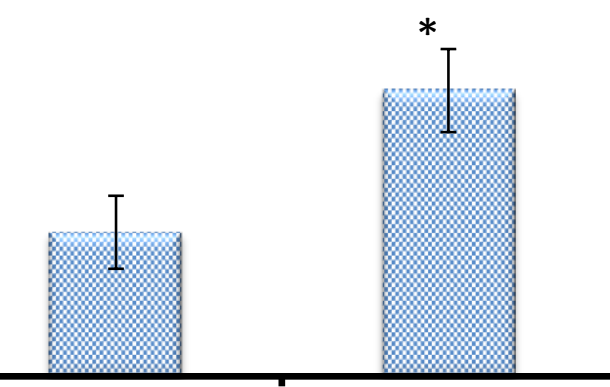

$\mathrm{C}$

Groups

HIIT

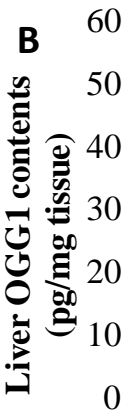

0

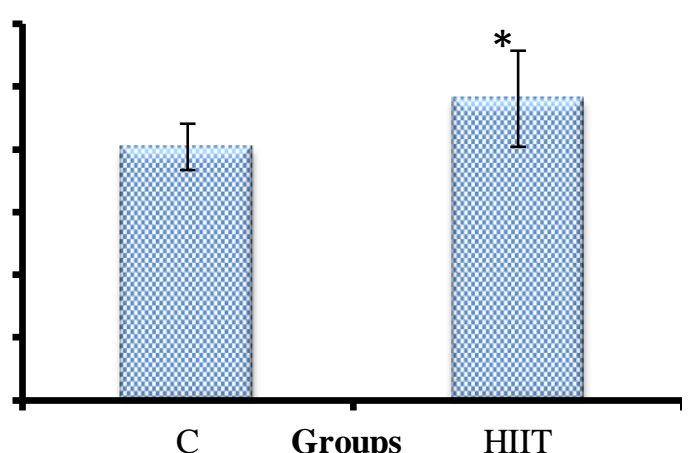

Groups

Fig. 1: Intensive interval training significantly increased OGG1 contents of brain (A) and liver (B). C; Control, HIIT; High intensive interval training.
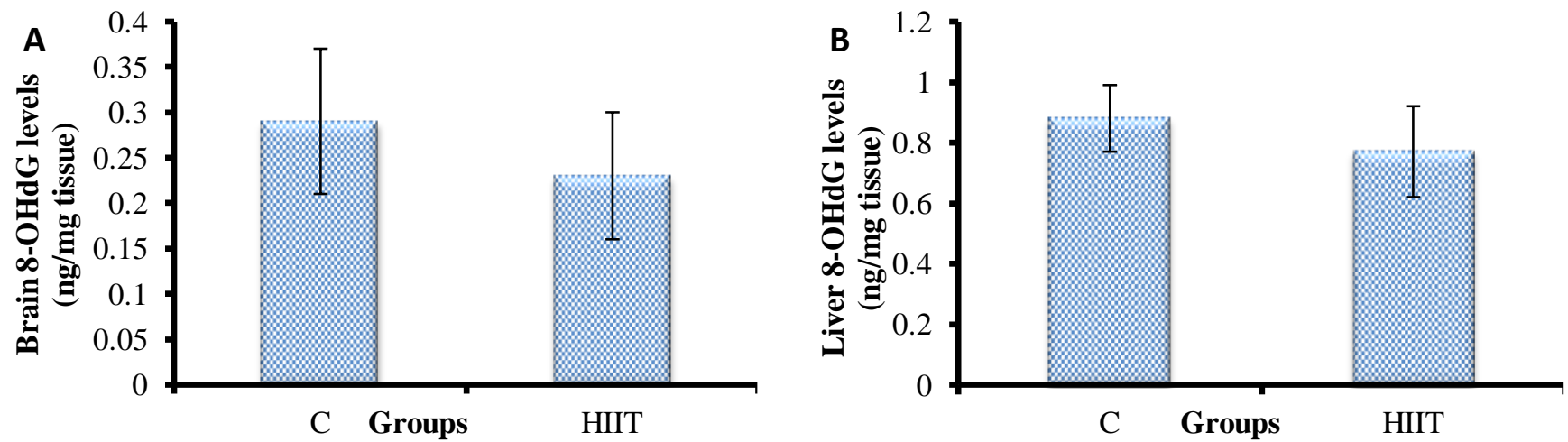

Fig. 2: Intensive interval training had no significant effect upon the 8-OHdG levels of brain (A) and liver (B). Abbreviations as donated in fig.1.

\section{DISCUSSION}

ROS generates by different sources in the cells including: mitochondrial electron transport chain, NADPH oxidase and xanthine oxidize (Ogonovszky et al., 2005a, 2005b). Although, ROS at low doses plays an important role at physiological processes (Radak et al., 2008), but ROS at large concentrations can modify oxidized lipids, proteins and DNA (Urso et al., 2003, Radak et al., 2008). Hence, cells are equipped with antioxidant and repairing enzymes to overcome stress oxidative conditions (Ogonovszky et al., 2005a, 2005b). OGG1, as main repair enzyme, expresses in all kinds of tissues with significantly different levels, recognizes and cleaves 8-OHdG from DNA (Ogonovszky et al., 2005a). There is now evidence that age (Radak et al., 2011), smoking (Park et al., 2011), $\mathrm{VO}_{2} \max$ (Loft et al., 1994), physical labor, BMI, inter-individual variation, nutrient (Kasai et al., 2001) and mental state, especially clinical depression (Forlenza et al., 2006), all affect OGG1 levels. Therefore, animal models were used in the present study to control the variables mentioned. In addition, it seems that observed changes in OGG1 and 8-OHdG are simply due to HIIT protocol. While two previous studies have been reported that running (Koltai et al., 2011) and swimming (Ogonovszky et al., 2005b) with low to moderate intensity have no significant influence on OGG1 and 8-OHdG levels in rat's hippocampus, our findings show an increase in OGG1 contents of brain and liver following HIIT. Our findings are supported by a study by Ogonovszky et al. (2005), who reported an increase in
OGG1 activity and 8-OHdG levels of rat liver following strenuous and overtraining (Ogonovszky et al., 2005a). This increasing is largely attributed to high number of mitochondria, higher metabolism of liver cells, and no significantly changes in SOD, GPX and catalase activity of liver cells following exercise (Ogonovszky et al., 2005a). In contrast, the level of DNA damage and OGG1 activity in brain did not significantly alter with increasing in exercise intensity (Ogonovszky et al., 2005b) due to increasing of antioxidant enzymes activity in different region of brain (Ogonovszky et al., 2005b).

Liver and brain, as two redox sensitive organs, react differently to changes in oxygen supply during exercise; however, adaptive processes related to oxidative challenges are very similar (Cooper et al., 2002, Urso et al., 2003, Lamprecht et al., 2004). Higher levels of iron and copper ions in the brain tissue increase the possibility of Fenton reaction (Cooper et al., 2002, Urso et al., 2003). Furthermore, higher production of ROS in the liver cells is associated to high density of mitochondria (Lamprecht et al., 2004, Cooper et al., 2002). In this regard, it is reported that $8-\mathrm{OHdG}$ levels in mitochondria of liver is 10 times higher than $8-\mathrm{OHdG}$ levels in nucleus because of close proximity to electron transport chain (Nakamoto et al., 2007). Furthermore, ischemia/blood reperfusion which occurs at the beginning and end of each set of intense exercise training increases the xanthine oxidase enzyme activity and subsequently damage to genomic structures (Lamprecht et al., 2004). However, in our study, HIIT had no significant effect upon the $8-\mathrm{OHdG}$ levels of brain and liver. 
Studies have been shown that OGG1 activity increases after 8 weeks of running on treadmill exercise (Nakamoto et al., 2007) and swimming training (Radak et al., 2009). In addition, it has been reported that voluntary wheel running increases the activity of antioxidant enzymes in different region of brain (Ogonovszky et al., 2005b; Jolitha et al., 2006). Collectively, no change in 8OHdG levels in brain and liver following HIIT may be attributed to higher levels of OGG1 activity (Nakamoto et al., 2007; Radak et al., 2009), higher levels of antioxidant enzyme activity (Ogonovszky et al., 2005a; Jolitha et al., 2006) and higher contents of OGG1 as shown in the present study. Interestingly, our results did not reveal any significant difference in changes of OGG1 and 8-OHdG between brain and liver. This suggests same response of OGG1 and $8-\mathrm{OHdG}$ levels in two mentioned organs following HIIT.

\section{CONCLUSION}

Separation of the training sessions to various bouts of exercise with maximum effort, through increase in OGG1 contents, will lead to modify of 8-OHdG levels in brain and liver.

\section{ACKNOWLEDGMENTS}

We thank the staff of the biochemistry laboratory at the Gonabad University of Medical Sciences for their valuable assistance with us in carrying out the biochemical assays.

\section{Financial support and sponsorship: Nil.}

Conflict of Interests: There are no conflicts of interest.

\section{REFRENCESS}

Afzalpour ME, Chadorneshin HT, Foadoddini M, Eivari HA. Comparing interval and continuous exercise training regimens on neurotrophic factors in rat brain. Physiol Behav, 2015; 147: 78-83.

Cooper C, Vollaard NB, Choueiri T, Wilson M. Exercise, free radicals and oxidative stress. Biochem Soc Trans, 2002; 30(2): 280-5.

Criswell D, Powers S, Dodd S, Lawler J, Edwards W, Renshler $\mathrm{K}$, Grinton S. High intensity training-induced changes in skeletal muscle antioxidant enzyme activity. Med Sci Sports Exerc, 1993; 25(10): 1135 40.

Cunningham P, Geary M, Harper R, Pendleton A, Stover S. High intensity sprint training reduces lipid peroxidation in fast-twitch skeletal muscle. JEPonline. 2005; 8(6): 18-25.

Forlenza MJ, Miller GE. Increased serum levels of 8-hydroxy2'-deoxyguanosine in clinical depression. Psychosom Med, 2006; 68(1): 17.

Haram PM, Kemi OJ, Lee SJ, Bendheim MØ, Al-Share QY, Waldum HL, Gilligan LJ, Koch LG, Britton SL, Najjar SM, Wisløff U. Aerobic interval training vs. continuous moderate exercise in the metabolic syndrome of rats artificially selected for low aerobic capacity. Cardiovasc Res, 2009; 81(4): 723-32.

Jolitha A, Subramanyam M, Devi SA. Modification by vitamin $\mathrm{E}$ and exercise of oxidative stress in regions of aging rat brain: studies on superoxide dismutase isoenzymes and protein oxidation status. Exp Gerontol, 2006; 41(8): 753-63.

Kasai H, Iwamoto-Tanaka N, Miyamoto T, Kawanami K, Kawanami S, Kido R, Ikeda M. Life style and urinary 8-hydroxydeoxyguanosine, a marker of oxidative DNA damage: effects of exercise, working conditions, meat intake, body mass index, and smoking. Jpn J Cancer Res, 2001; 92(1): 9-15.
Koltai E, Zhao Z, Lacza Z, Cselenyak A, Vacz G, Nyakas C, Boldogh I, Ichinoseki-Sekine N, Radak Z. Combined exercise and insulinlike growth factor-1 supplementation induces neurogenesis in old rats, but do not attenuate age-associated DNA damage. Rejuvenation Res, 2011; 14(6): 585-96.

Kostaropoulos I, Nikolaidis M, Jamurtas A, Ikonomou G. Comparison of the blood redox status between long-distance and shortdistance runners. Physiol Res, 2006; 55(6): 611.

Lamprecht M, Greilberger J, Oettl K. Analytical aspects of oxidatively modified substances in sports and exercises. Nutrition, 2004 20(7-8): 728-30

Loft S, Astrup A, Buemann B, Poulsen HE. Oxidative DNA damage correlates with oxygen consumption in humans. FASEB J, 1994; 8(8): 534-7.

Nakamoto H, Kaneko T, Tahara S, Hayashi E, Naito H, Radak $\mathrm{Z}$, et al. Regular exercise reduces 8-oxodG in the nuclear and mitochondrial DNA and modulates the DNA repair activity in the liver of old rats. Exp Gerontol, 2007; 42(4): 287-95.

Nikolaidis MG, Jamurtas AZ. Blood as a reactive species generator and redox status regulator during exercise. Arch Biochem Biophys, 2009; 490(2): 77-84.

Ogonovszky H, Berkes I, Kumagai S, Kaneko T, Tahara S, Goto S, Radák Z. The effects of moderate-, strenuous-and over-training on oxidative stress markers, DNA repair, and memory, in rat brain. Neurochem Int, 2005b; 46(8): 635-40.

Ogonovszky H, Sasvári M, Dosek A, Berkes I, Kaneko T, Tahara S, Nakamoto H, Goto S, Radák Z. The effects of moderate, strenuous, and overtraining on oxidative stress markers and DNA repair in rat liver. Can J Appl Physiol, 2005a; 30(2): 186-95.

Park K-S, Lee Y. Lymphocyte apoptosis in smokers and nonsmokers following different intensity of exercises and relation with lactate. Int J Exerc Sci, 2011; 4(3): 204-216.

Radák Z, Apor P, Pucsok J, Berkes I, Ogonovszky H, Pavlik G, Nakamoto H, Goto S. Marathon running alters the DNA base excision repair in human skeletal muscle. Life Sci, 2003; 72(14): 1627-33.

Radak Z, Atalay M, Jakus J, Boldogh I, Davies K, Goto S. Exercise improves import of 8-oxoguanine DNA glycosylase into the mitochondrial matrix of skeletal muscle and enhances the relative activity. Free Radic Biol Med, 2009; 46(2): 238-43.

Radak Z, Bori Z, Koltai E, Fatouros IG, Jamurtas AZ, Douroudos II, et al. Age-dependent changes in 8-oxoguanine-DNA glycosylase activity are modulated by adaptive responses to physical exercise in human skeletal muscle. Free Radic Biol Med, 2011; 51(2): 417-23.

Radak Z, Chung HY, Goto S. Systemic adaptation to oxidative challenge induced by regular exercise. Free Radical Biology and Medicine. 2008;44(2):153-9.

Radak Z, Kumagai S, Nakamoto H, Goto S. 8-Oxoguanosine and uracil repair of nuclear and mitochondrial DNA in red and white skeletal muscle of exercise-trained old rats. Journal of Applied Physiology. 2007;102(4):1696-701.

Radak Z, Toldy A, Szabo Z, Siamilis S, Nyakas C, Silye G, et al. The effects of training and detraining on memory, neurotrophins and oxidative stress markers in rat brain. Neurochemistry international. 2006;49(4):387-92

Rasmussen P, Brassard P, Adser H, Pedersen MV, Leick L, Hart E, et al. Evidence for a release of brain-derived neurotrophic factor from the brain during exercise. Experimental physiology. 2009; 94(10): 1062-9.

Urso ML, Clarkson PM. Oxidative stress, exercise, and antioxidant supplementation. Toxicology. 2003;189(1):41-54.

\section{How to cite this article:}

Afroozi-Gerow E, Afzalpour ME, TaheriChadorneshin H, AbtahiEivary SH. Effect of high intensity interval training on 8oxoguanine DNA glycosylase and 8-hydroxy-2'-deoxyguanosine contents in the brain and liver of rats. J App Pharm Sci, 2016; 6 (10): $170-173$. 